\title{
Delayed Coronary Occlusion After Transcatheter Aortic Valve Replacement in an Elderly Patient with Atrial Fibrillation
}

\section{Sara Çetin Şanlıalp1, ๑ Özer Eser², ๑ Musa Şanlıalp2}

${ }^{1}$ Servergazi State Hospital, Clinic of Cardiology, Denizli, Turkey

2Denizli State Hospital, Clinic of Cardiology, Denizli, Turkey

\begin{abstract}
Transcatheter aortic valve replacement (TAVR) is an effective procedure in selected patients with symptomatic severe aortic stenosis. However, the complications associated with TAVR are still an important problem today. One of the life-threatening complications associated with TAVR is coronary occlusion, which requires immediate diagnosis and intervention. This serious complication also leads to poor prognosis and mortality. In this case, we aimed to present the late coronary artery occlusion due to thrombus after TAVR and to emphasize the uncertainties and complexities in antithrombotic treatment in patients with TAVR, which may lead to catastrophic outcomes, especially in patients with atrial fibrillation.
\end{abstract}

Keywords: Coronary occlusion, myocardial infarction, transcatheter aortic valve replacement

\section{Introduction}

Aortic stenosis (AS) is a valvular heart disease that affects $5 \%$ of the elderly population ${ }^{(1)}$. Transcatheter aortic valve replacement (TAVR) has become the gold standard treatment option for patients with severe symptomatic
AS and high or moderate risk for surgical aortic valve replacement ${ }^{(2)}$. Although the results of the TAVR procedure are positive over time and the complications decrease, the risk of life-threatening complications still remains. One of these is coronary occlusion $(\mathrm{CO})$, which can have

Address for Correspondence: Sara Çetin Şanlıalp, Servergazi State Hospital, Clinic of Cardiology, Denizli, Turkey e-mail: saracetin@hotmail.com.tr ORCID: orcid.org/0000-0001-9328-9197

Received: 12.11.2020 Accepted: 04.12.2020

Cite this article as: Çetin Şanlıalp S, Eser Ö, Şanlıalp M. Delayed Coronary Occlusion After Transcatheter Aortic Valve Replacement in an Elderly Patient with Atrial Fibrillation. EJCM 2020;8(4):206-210.

DOI: 10.32596/ejcm.galenos.2020.11.066 
fatal consequences and is usually seen in the acute phase immediately after valve insertion. However, several cases of delayed coronary occlusion (DCO) have also been reported recently ${ }^{(3,4)}$. Therefore, we aimed to discuss an AF patient who was admitted to emergency department with acute myocardial infarction due to $\mathrm{CO}$ in the late period after TAVR procedure in this case report.

\section{Case Report}

An 84-year-old female patient was admitted to the cardiology outpatient clinic with recurrent syncope attacks. She was under treatment with Dabigatran $110 \mathrm{mg} 2 \mathrm{x} 1$ for $\mathrm{AF}$ and had no any documented cardiovascular diseases or cardiovascular risk factors such as hypertension and diabetes mellitus (DM). Her resting ECG showed normal ventricular responsive AF and left bundle branch block morphology. In the transthoracic echocardiography (TTE), aortic valve area was $0.82 \mathrm{~cm}^{2}$, aortic velocity was $5.2 \mathrm{~m} / \mathrm{s}$ and transaortic mean gradient was $52 \mathrm{mmHg}$. The left ventricular ejection fraction (LVEF) was measured as $55 \%$ by biplanar Simpson method and there was no wall motion abnormality. In addition, she underwent neurological evaluation and magnetic resonance imaging was performed due to recurrent syncope attacks. After the exclusion of cerebrovascular disease, TAVR procedure was planned because of the high surgical risk calculated by EuroSCORE method (27.3\%). Coronary computed tomography (CT) angiography demonstrated the coronary ostium height as $18.5 \mathrm{~mm}$, the sinus of valsalva diameter as $30.5 \mathrm{~mm}$, and the sinotubular junction as $33 \mathrm{~mm}$. On coronary $\mathrm{CT}$ angiographic images, the left main coronary artery (LMCA) and left anterior descending (LAD) coronary artery were normal, there was no significant lesion $(<50 \%)$ in the right coronary artery (RCA) and there were plaque formations in the circumflex coronary artery $(\mathrm{Cx})$ (Figure 1). Due to the absence of significant lesion, the invasive coronary angiography was not planned and the $29 \mathrm{~mm}$ Medtronic Core Valve was implanted successfully via the right transfemoral route (Figure 2). After implantation, the dabigatran $110 \mathrm{mg} 2 \times 1$ was switched to edoxaban $60 \mathrm{mg}$ due to ease of use of single-dose and positive outcomes of
ENGAGE AF-TIMI 48 trial $^{(5)}$ (Effective Anticoagulation with Factor Xa Next Generation in Atrial Fibrillation-

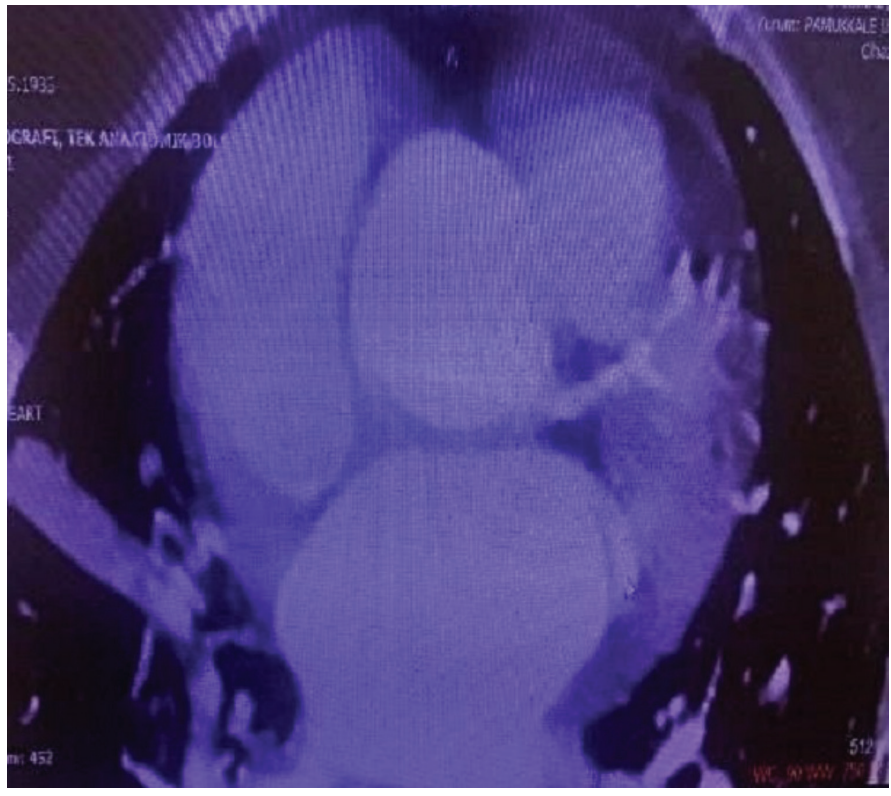

Figure 1. Imaging of the left main coronary artery (LMCA), left anterior descending artery (LAD) and Circumflex artery $(C x)$ in $C T$ coronary angiography before TAVR procedure CT: Computed tomography, TAVR: Transcatheter aortic valve replacement

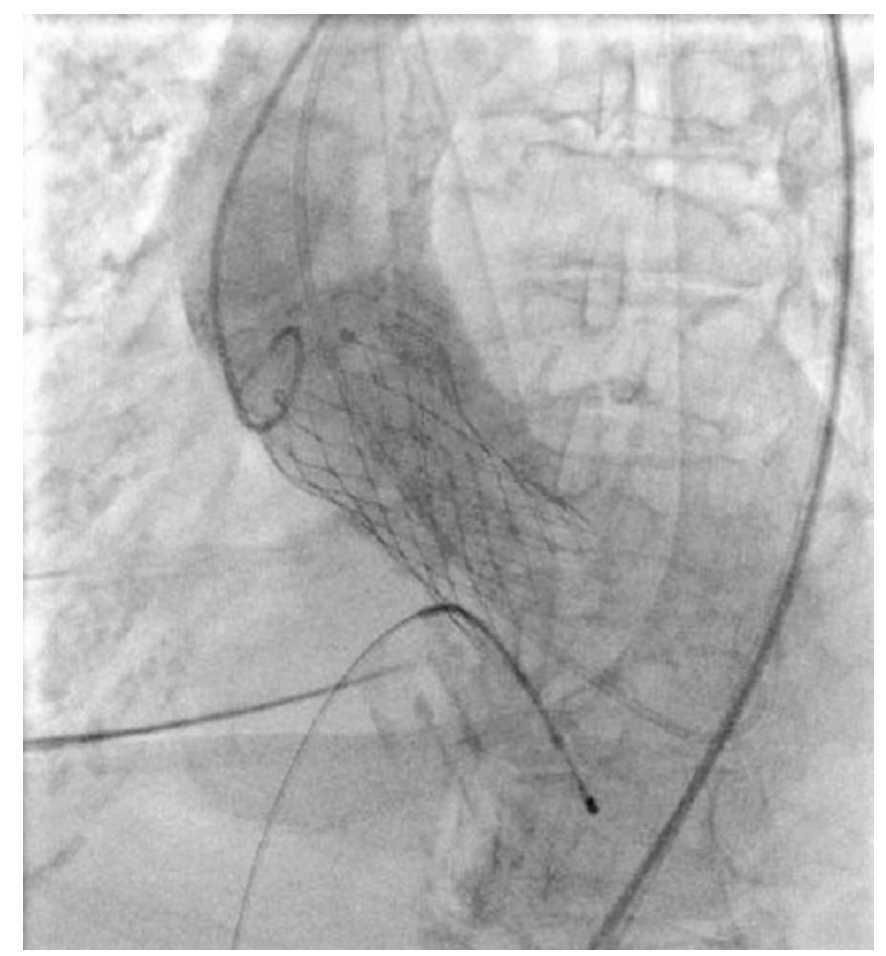

Figure 2. Angiographic view of the bioprosthetic aortic valve 
Thrombolysis in Myocardial Infarction 48) in subgroup analysis of AF patients with TAVR. She was followed up with dual antithrombotic therapy consisting of $60 \mathrm{mg}$ edoxaban and $75 \mathrm{mg}$ clopidogrel after discharge. After three months of dual antithrombotic treatment, clopidogrel was stopped and continued with only edoxaban. No complication was reported, such as bleeding or thromboembolism during the first six months of followup. In serial TTE imagings, the mean transaortic valve gradient was $10 \mathrm{mmHg}$ and aortic velocity was $1.4 \mathrm{~m} / \mathrm{s}$ and there was no paravalvular leakage in bioprosthetic valve. However, in eight months after implantation, she was admitted to the emergency department in the third hour of chest pain. Her family reported that she had taken oral anticoagulants regularly and she had recurrent angina attacks for the last 3 days. At admission, peripheral pulses were weak and her blood pressure was 60/40 $\mathrm{mmHg}$. EKG showed diffuse ST elevation in anterior leads with reciprocal changes in inferior leads (Figure $3)$. In bedside echocardiography, there was no problem in the bioprosthetic valve but the LVEF was $40 \%$ with hypokinesia at the anterior wall and septum. Clopidogrel $300 \mathrm{mg}$, acetylsalicylic acid (aspirin) $300 \mathrm{mg}$ were given in the emergency department. She underwent cardiac catheterization by positive inotropic support due to hemodynamic deterioration and the door-to-balloon time was nearly 25-30 minutes. Coronary angiography showed

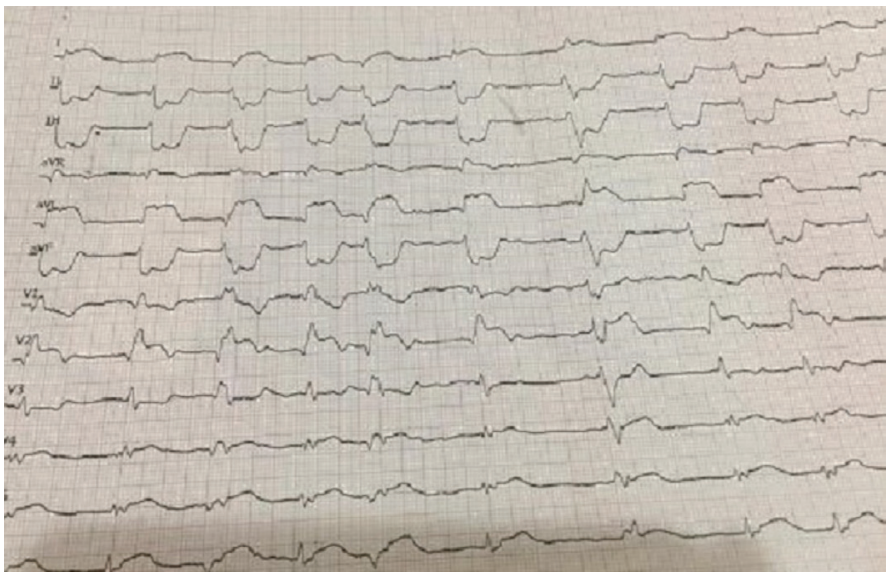

Figure 3. Diffuse ST elevation in anterior leads and reciprocal changes in inferior leads on ECG due to coronary occlusion the total occlusion of the ostium of LMCA with thrombus and percutaneous coronary intervention (PCI) was planned (Figure 4). Before the balloon angioplasty of $\mathrm{Cx}$ artery and LAD artery, intravenous $5000 \mathrm{IU}$ of unfractionated heparin was used and three drug-eluting stents were implanted into LAD artery. However, the Thrombolysis in Myocardial Infarction (TIMI) flow grade III could not be supplied (Figure 5). She developed cardiac arrest one hour after cardiac catheterization. Unfortunately, she did not restore life by cardiopulmonary resuscitation and passed away.

\section{Discussion}

The TAVR procedure has become common in patients who are not suitable for surgical procedures in severe AS. However, this procedure is still associated with complications such as conduction defects, vascular complications, thromboembolic events and paravalvular leakage. $\mathrm{CO}$ after TAVR procedure is a rare life-threatening complication and was was described by Webb et al's study $^{(6)}$. CO is more common in LMCA than RCA due to the higher localization of the right coronary ostium ${ }^{(7)}$. This complication usually develops acutely after the

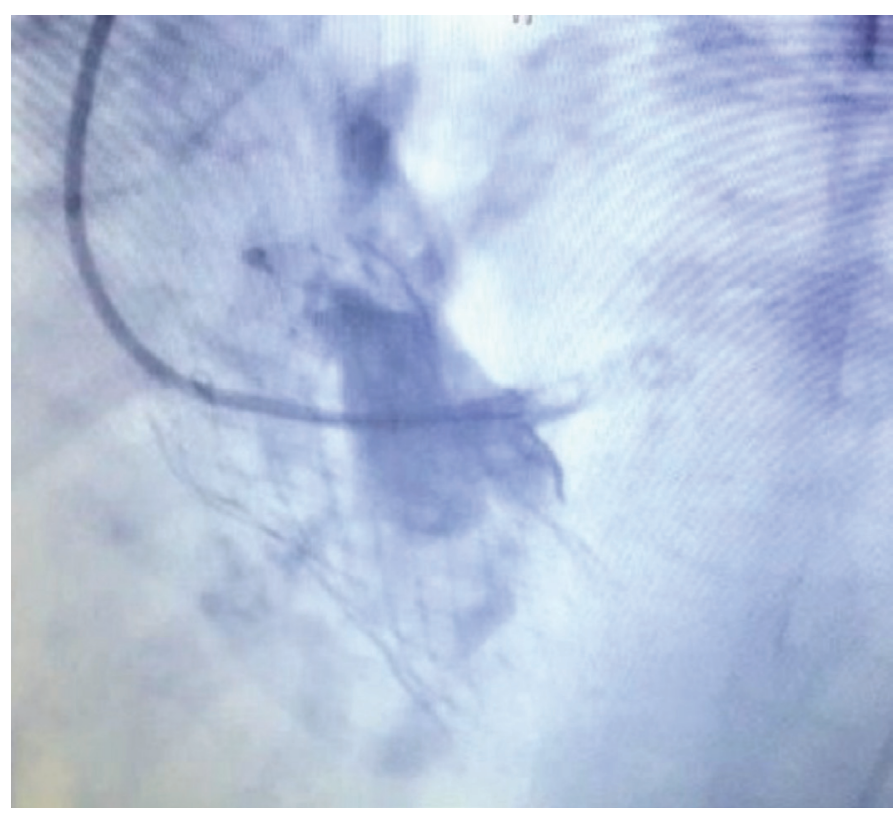

Figure 4. Angiographic view of the thrombus in the left coronary ostium 

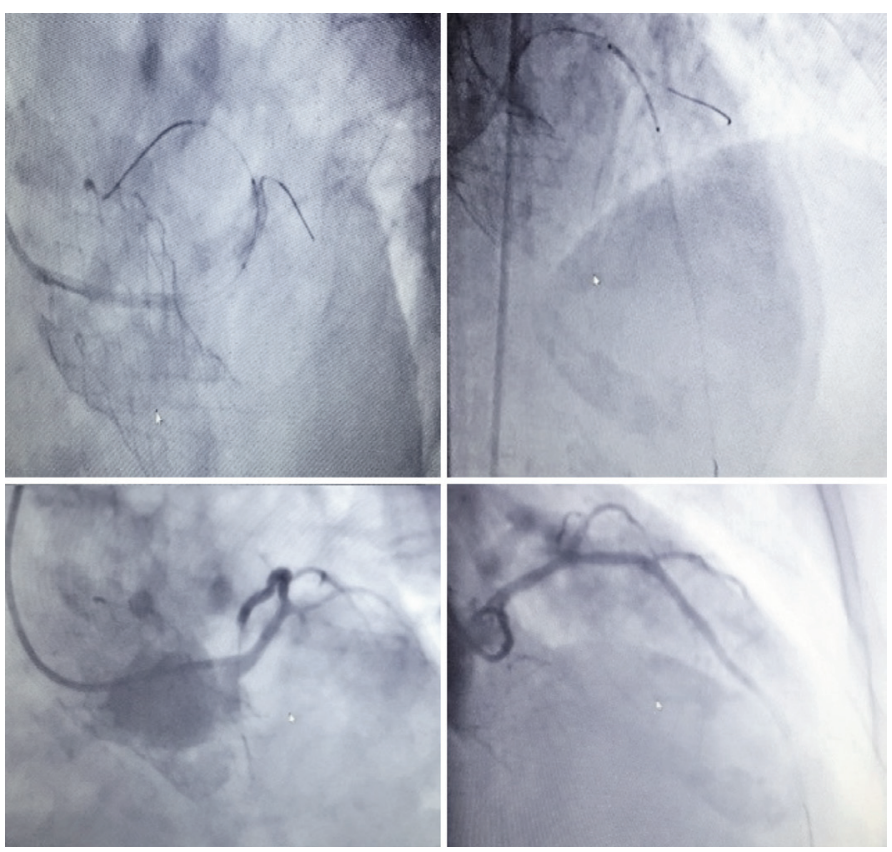

Figure 5. In angiographic views, ensuring of the TIMI 2 grade flow in coronary vessels by percutaneous coronary intervention TIMI: The Thrombolysis in Myocardial Infarction score

TAVR procedure and malposition of the device or natural valve leaflets protrusion or plaque migration in natural valve during the procedure may obliterate the coronary ostia $^{(8)}$ due to anatomic factors such as shallow sinuses of valsalva $(<30 \mathrm{~mm})$, low localization of coronary ostium $(<12 \mathrm{~mm})$, narrow aortic root, presence of plaque in LMCA and serious calcification of aortic valve cusps. In addition advanced age, female sex, co- existing coronary artery disease, balloon-expandable valves and valve-invalve implantation increase the risk of $\mathrm{CO}^{(6,7,9)}$.

DCO is the late occlusion of the coronary ostia after the successful TAVR procedure. DCO is usually detected during angiography, surgery or autopsy. DCO is always associated with the TAVR procedure and its incidence has been reported as $0.22 \%$ in the studies of case series ${ }^{(3)}$. Little is known about how pathophysiologic alterations at the macro and microvascular levels lead to long-term DCO. Although the mechanisms of DCO formation are not clear, theoretically these mechanisms are the presence of the device material, late endothelization hypersensitivity reactions, high wall shear stress, blood flow variability and hemodynamic interactions between these factors ${ }^{(8)}$.

In our view, the left main coronary ostium was occluded by thrombus as a complication of TAVR procedure rather than coronary artery diseases. We may explain the thrombus formation in two ways: a) Early opening and closing of prosthetic valves may lead to leaflet thrombosis by blood stasis in the sinus valsalva area and the separated thrombus from the valve leaflet may occlude the coronary ostium due to dynamical blood flow (embolization), b) thrombus formation may occur in the coronary vessels due to intracoronary stasis due to early termination of the diastolic phase causing by the rigid bioprosthesis valve (de novo thrombosis) ${ }^{(8)}$. In this report, the presence of $\mathrm{AF}$, senility, normal LMCA in coronary $\mathrm{CT}$ imagings and absence of the cardiovascular risk factors may strengthen our view. However, we could not explain which way was responsible for the mechanism of the thrombus formation (by de novo thrombosis or embolization) using multidetector CT scanning because of death in the first hour of PCI.

Another important factor associated with $\mathrm{CO}$ may be the lack of effective antithrombotic treatment strategies after TAVR procedure. Especially in AF patients with TAVR, who have high risk of thromboembolism, the antiplatelet therapy is more complex. Proposed treatment schemes are based on small studies and expert opinions. In the guidelines, there are inconsistencies and contradictions about which antiplatelet and anticoagulant agents should be used and how long the dual antithrombotic treatment will be continued in patients with AF after the TAVR procedure $^{(10)}$. Therefore, empirical therapy or early termination of dual antithrombotic therapy may also accelerate the thrombus formation in the coronary ostium in this case report.

In conclusion, late thrombus-induced $\mathrm{CO}$ after TAVR procedure is very rare and it may lead to serious outcomes. This complication should be considered when a patient undergoes the TAVR procedure and presents with cardiac collapse, myocardial infarction or ventricular arrhythmia. 
Inconsistencies and contradictions in treatment strategies may lead to thromboembolic complications after the TAVR procedure, especially in patients with AF. Due to deficiencies in antithrombotic treatment strategies, the patients with high risk may be periodically screened with the multi-detector CT scanning if TTE is not sufficient. In addition, large randomized controlled trials are needed to determine the effective antithrombotic treatment strategies accepted by the large population.

\section{Ethics}

Informed Consent: Informed consent was obtained from the patient's family.

Peer-review: Externally peer-reviewed.

\section{Authorship Contributions}

Surgical and Medical Practices: Ö.E., S.Ç.Ş., M.Ş., Concept: S.Ç.Ş., Design: S.Ç.Ş., Data Collection or Processing: Ö.E., M.Ş., Analysis or Interpretation: Ö.E., M.Ş., Literature Search: S.Ç.Ş., Writing: S.Ç.Ş.

Conflict of Interest: No conflict of interest was declared by the authors.

Financial Disclosure: The authors declared that this study received no financial support.

\section{References}

1. Siqueira D, Abizaid A, Arrais M, Sousa JE. Transcatheter aortic valve replacement in elderly patients. J Geriatr Cardiol 2012;9:78-82.

2. Mark PR, Peter K, McFadyen JD. Thromboembolic and bleeding complications in transcatheter aortic valve implantation: insights on mechanisms, prophylaxis and therapy. J Clin Med 2019;25:8:280.

3. Jabbour RJ, Tanaka A, Colombo A, Latib A. Delayed coronary occlusion after transcatheter aortic valve implantation: implications for new transcatheter heart valve design and patient management. Interv Cardiol 2018:13:137-9.

4. Kennon S. Delayed coronary obstruction after transcatheter aortic valve implantation is not the structural equivalent of late stent thrombosis after percutaneous coronary intervention. Interv Cardiol 2018;13:60-1.

5. Carnicelli AP, De Caterina R, Halperin JL, et al. ENGAGE AF-TIMI 48 Investigators. Edoxaban for the prevention of thromboembolism in patients with atrial fibrillation and bioprosthetic valves. Circulation 2017;135:12735 .

6. Webb JG, Chandavimol M, Thompson CR, et al. Percutaneous aortic valve implantation retrograde from the femoral artery.Circulation 2006;113:84250 .

7. Ramirez R, Ovakimyan O, Lasam G, Lafferty K. A very late presentation of a right coronary artery occlusion after transcatheter aortic valve replacement. Cardiol Res 2017;8:131-3.

8. Yalta K, Zorkun C, Yilmaztepe M, Gurlertop Y. Late coronary ischemic syndromes associated with transcatheter aortic valve implantation: A review of mechanistic and cilinical aspects. Indian Heart J 2018;70:901-6.

9. Paradis JM, Fried J, Nazif T, et al. Aortic stenosis and coronary artery disease: What do we know? What don't we know? A comprehensive review of the literature with proposed treatment algorithms. Eur Heart J 2014;35:2069-82.

10. Valvo R, Costa G, Tamburino C, Barbanti M. Antithrombotic theraphy in transcatheter aortic valve replacement. Front. Cardiovasc. Med 2019;6:73. 